\title{
POLÍTICAS PÚBLICAS EM SAÚDE, SISTEMA ÚNICO DE SAÚDE E O PAPEL DO LEGISLATIVO MUNICIPAL: UM ESTUDO SOBRE OS PROJETOS DE LEI ORDINÁRIA NA ÁREA DA SAÚDE DA CIDADE DE CURITIBA NO PERÍODO 2008 $-2011$
}

\author{
PUBLIC POLICIES IN HEALTH, SINGLE HEALTH SYSTEM AND THE ROLE OF \\ MUNICIPAL LEGISLATIVE: A STUDY ON THE DRAFT COMMON LAW IN \\ HEALTH CURITIBA CITY THE PERIOD 2008 - 2011
}

\author{
Marta Chaves Vasconcelos ${ }^{1}$ \\ Christian Luiz da Silva ${ }^{2}$ \\ Cristiano Vieira Rotta ${ }^{3}$
}

\section{RESUMO}

As políticas públicas de saúde institucionalizadas pelo Sistema Único de Saúde (SUS) universalizaram os serviços e fortaleceram os conselhos municipais e as administrações públicas municipais para o gerenciamento deste sistema no âmbito local. Esse artigo descreve e avalia os projetos lei ordinária especificamente da área da saúde na cidade de Curitiba no período de 2008 a 2011, com intuito de estabelecer elementos práticos para contribuição deste poder municipal para a consolidação das políticas públicas de saúde no município. Trata-se de uma pesquisa exploratória e aplicada, com uso de fonte de dados secundários e análise quantitativa das informações. Os projetos da área da saúde representam 16,2\% do total de projetos lei ordinária, totalizando 96 projetos, esses focam em grande parte da população e fortalecem algumas datas comemorativas. Quanto aos partidos políticos, pode-se observar que há partidos com menor quantidade de vereadores, entretanto propuseram mais projetos lei do que outros partidos políticos com maior número de vereadores. Os resultados demonstram a necessidade de maior integração e participação da sociedade no Conselho Municipal de Saúde e no debate das proposições do Poder Legislativo municipal para fortalecer o papel local no desenvolvimento e aprimoramento da política pública em saúde.

Palavras-chave: Poder legislativo. Sistema Único de Saúde. Projeto de Lei. Lei Ordinária e Saúde.

\section{ABSTRACT}

\footnotetext{
${ }^{1}$ Universidade Tecnológica Federal do Paraná. Graduada em Bacharelado em Administração pela Universidade Tecnológica Federal do Paraná. Av. Sete de Setembro, 3165 - Rebouças CEP 80230-901 - Curitiba - PR - Brasil Telefone Geral +55 (41) 3310-4545. martacvasconcelos@hotmail.com.

2 Universidade Tecnológica Federal do Paraná. Coordenador Adjunto dos Mestrados Profissionais dos programas de pós-graduação da Capes na área de Planejamento Urbano e Regional e Demografia. Professor permanente do mestrado e doutorado do Programa de Pós-graduação de Tecnologia (PPGTE). Professor permanente do Programa de Pós-graduação em Planejamento e Governança Pública (mestrado profissional) da UTFPR. Graduado em economia, mestre e doutor em engenharia de produção e pós-doutor em administração pela USP. christianlsilva76@gmail.com.

3 Universidade Tencológica Federal do Paraná. Possui graduação em Educação Física pela Universidade Tecnológica Federal do Paraná (UTFPR), 2010. Mestrado em Planejamento e Governança Pública- UTFPR, (2011-2013).cristiano.mahatma3@hotmail.com.
} 
The public health policies institutionalized by the Unified Health System (SUS) universalized services and strengthened the municipal councils and municipal governments for the management of this system at the local level. This article describes and evaluates the ordinary law projects specifically in the health field in Curitiba from 2008 to 2011, aiming to establish practical elements for contribution of municipal power to the consolidation of public health policies in the municipality. This is an exploratory and applied research, using secondary source of data and quantitative analysis of the information. The healthcare projects represent $16.2 \%$ of total ordinary law projects totaling 96 projects, these focus on much of the population and strengthen some holidays. As for political parties, it can be seen that there are parties with fewer councilors, however most projects proposed law than other political parties with the largest number of councilors. The results demonstrate the need for greater integration and participation of society in the Municipal Health Council and discussion of propositions of Power City Council to strengthen the local role in developing and improving public policy in health.

Keywords: Legislature. Health System. Bill. Ordinary and Health Law.

\section{Introdução}

As políticas públicas de saúde institucionalizadas pelo Sistema Único de Saúde universalizaram os serviços e fortaleceram os conselhos municipais e as administrações públicas municipais para o gerenciamento deste sistema no âmbito local.

O sistema de saúde brasileiro é composto por um grande sistema público, gerido pelo governo, chamado Sistema Único de Saúde (SUS), que serve a maioria da população, e também pelo setor privado, gerido por fundos de seguros de saúde privados e empresários.

O Sistema Único de Saúde (SUS) é um sistema, composto por muitas partes e, por mais diferentes que pareçam, tem uma finalidade comum: cuidar e promover a saúde de toda a população, melhorando a qualidade de vida dos brasileiros (SILVA; ROTTA, 2012). Contudo, o poder legislativo tem um papel representativo na definição de normas e leis que orientam a organização e o atendimento deste sistema no município.

O Estado tem manifestado a sua vontade, predeterminando normas jurídicas a serem coativamente respeitadas, de maneira que cada cidadão possa realizar seus interesses individuais, sem prejuízo ao interesse coletivo. Assim, interferindo na vida social, o poder estatal estabelece normas que asseguram a vida em sociedade. A legislação é o instrumento de que se serve o Estado para ditar essas normas de direito.

A Constituição Federal consagrou em seu art. $2^{\circ}$ a tradicional tripartição de Poderes ao afirmar que são Poderes do Estado, independentes e harmônicos entre si, o Legislativo, o Executivo e o Judiciário. São as chamadas funções típicas e atípicas. As funções típicas do Poder Legislativo são legislar e fiscalizar, tendo ambos o mesmo grau de importância. As funções atípicas constituem-se em administrar e julgar (MORAES, 2010). 
No âmbito municipal o poder legislativo é representado pelos vereadores, suas principais atribuições são: fiscalizar a ação do prefeito, garantindo que os recursos sejam aplicados de acordo com o que estabelece a lei; apresentar e aprovar leis que melhorem a cidade e a qualidade de vida de seus moradores; atender às reivindicações de cada comunidade que os elegeu como seus representantes. Este artigo delimita-se em avaliar a penúltima função do legislativo.

Esse artigo tem como principal objetivo descrever a avaliar os projetos de lei ordinária especificamente da área da saúde na cidade de Curitiba no período de 2008 a 2011, com intuito de estabelecer elementos práticos para contribuição deste poder municipal para a consolidação das políticas públicas de saúde no município.

O pressuposto deste trabalho fundamenta-se na importância do poder legislativo para compor as ações públicas do Estado na área da saúde na esfera municipal que especializam e qualifiquem as políticas públicas de saúde implementadas no âmbito municipal.

Para tanto, esse trabalho contribuirá para a sociedade e a academia, pois a população poderá verificar quais são as proposições que o legislativo municipal da cidade de Curitiba está propondo e quais foram aprovadas/sancionadas, vetadas e ainda estão em votação. Contribuirá para a academia, pois por meio desse trabalho é possível criar um comparativo com anos anteriores, bem como aplicar a mesma metodologia em outras cidades.

Este artigo está organizado em 5 seções, incluindo esta introdução. A próxima seção define política pública em saúde e o Sistema Único de Saúde, relacionando o tema com a ação local por meio da intervenção do legislativo municipal. A terceira seção detalha a metodologia de pesquisa e a base de dados utilizada e tratada para obtenção dos dados. A quinta seção apresenta os resultados da pesquisa e a sexta seção finaliza com as considerações finais.

\section{A Política Pública em Saúde e o Sistema Único de Saúde (SUS)}

O Brasil é um país democrático e a função do Estado é tornar mais equitativa as oportunidades a fim de amadurecer a soberania e o processo do desenvolvimento nacional. A democracia necessita de diálogo entre o Estado e a sociedade e esse diálogo acontece não somente por meio do voto, mas também com a participação da sociedade em audiências públicas, encontros, assembleias, conferência e outros meios, de forma com que tenha maior interação entre o Estado e a sociedade (SILVA, 2012).

Nesse contexto complexo, o desafio de amadurecimento do Estado brasileiro depende de governos e de políticas públicas inovadoras que permitam a inclusão da 
população na condição de cidadão digno e capaz de tomar suas decisões e contribuir para o desenvolvimento nacional. Pois a intervenção do governo ocorre pelas políticas públicas. Apenas o governo pode implementá-las porque possui a capacidade de universalização, coerção e regulamentação e pode adotar medidas de caráter universal, que atenda todo o povo ou de forma generalizada tenha maior poder de alcance local. Estas políticas públicas inovadoras são cada vez mais descentralizadas, para se adaptarem à estrutura e às condições da realidade local (SILVA, 2012).

No entanto, Birkland (2005) afirma que não há um consenso sobre o próprio conceito de políticas públicas, entretanto alguns atributos se destacam: a política é feita em nome do público; a política é geralmente feita ou iniciada pelo governo; política é interpretada e implementada por atores públicos e privados; política é o que o governo intenciona fazer; política é o que o governo escolhe não fazer.

Mead (1995, apud SOUZA, 2006) a define como "um campo dentro do estudo da política que analisa o governo à luz de grandes questões públicas”. Já Laswell (1958, apud SOUZA, 2006) a define como "decisões e analises sobre política pública implicam responder às seguintes questões: quem ganha o quê, por que e que diferença faz". Peters (1986) define política pública como a soma das atividades dos governos, que agem diretamente ou através de delegação e que influenciam a vida dos cidadãos.

Dye $(2011$, p. 1) busca não entrar nesta controvérsia ao sintetizar a definição de políticas públicas como "o que o governo escolhe fazer ou não fazer". Isso significa, para o autor, que a inação do governo pode ter grandes impactos sobre a sociedade como as ações do governo. Para Dye (2011, p. 9) as demais definições apenas detalham aspectos ou características, mas tem o mesmo sentido.

Independente do autor, todas as definições apontam para os governos, onde as ideias são concebidas e as decisões tomadas, e, apesar das diferentes abordagens, as definições mantêm a perspectiva de que o todo é mais importante que as partes, onde os indivíduos, instituições, interações, ideologia e interesses contam mesmo existindo diferenças sobre a importância relativa dos mesmos (SOUZA, 2006).

A política pública surge de problemas de interesse coletivo que se materializam na discussão e constituição de diferentes grupos de interesses que exportam visões e objetivos legítimos àquela discussão. Cada grupo tem capacidade de articulação e argumentação diferenciada por conta da própria visão e forma de resolver aquele problema. Esta discussão se consolida em diferentes ambientes que constituem uma arena política. A arena é um processo de discussão na sociedade. A discussão se consolida em alternativas para "solução" 
daquele problema de interesse coletivo que irá constituir a intenção de formalização e legitimidade da Política. Essa intenção constitui a diretriz da Política Pública que irá se materializar pela ação do Governo na sua implementação. Ao ser implementada a política pode "solucionar" ou não o problema. Essa é a discussão sobre a sua efetividade. A efetividade é a transformação de uma realidade em torno daquele problema e as vinculações pertinentes entre os grupos de interesse. Se a Política Pública avançou para solucionar aquele problema e mudar a realidade local, então ela é efetiva e a ação e a intenção deram conta daquela situação e melhorou a condição de vida da população. Se não conseguiu lidar com o problema e este continua, não foi efetivo e pode ter diferentes razões interesses de grupos mais consolidados apontaram estratégias paliativas e não afetivas, incapaz de articular uma proposta e intenção efetiva, ação muito distante da intenção, entre outros (figura 1).

Figura 1 - Ciclo de Políticas Públicas

\section{Percepção e \\ Definição do Problema}

\section{Formação da Agenda}

\section{Monitoramento \\ e Avaliação}

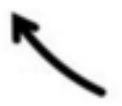

Ciclo de Políticas Públicas

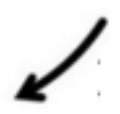

\section{Formulação de} Programas e Projetos

\section{Implementação} das Políticas

Fonte: Criado pelos autores.

Já as políticas públicas de saúde podem ser entendidas como as respostas sociais (agir ou resguardar) de uma instituição, dotada de poder legitimado pela sociedade (Estado) diante das condições de saúde individuais e coletivas e de seus determinantes (habitação, emprego, educação, lazer e etc.), bem como da produção, da distribuição, da gestão e da regulamentação de bens e serviços atrelados à saúde e ao ambiente (PAIM; TEIXEIRA, 2006). 
A política de saúde não contraria outras políticas, mas estabelece-se na arena conflituosa e dinâmica de poder, especificamente em saúde (politics), bem como as que se referem à regulamentação e normatização de diretrizes, planos e programa de saúde (policy) (PAIM; TEIXEIRA, 2006). Esta relação de poder e normatização com regência do Estado como mediador de saúde individual e coletiva legitima a medicina societariamente como responsável pelos cuidados dos enfermos.

Em um primeiro momento, na transição de saberes entre os arcaicos dogmáticos para o científico, o que demarcava a presença do Estado na configuração do saber médico era representado pela Sereníssima República de Veneza, um Estado liberal e tolerante no meio de uma Europa feudal, imperialista e pontifícia. Em segundo momento, a fundamentação do papel do Estado no final do século XIX, no qual o interesse pela saúde da população fez com que o Estado atendesse às reivindicações dos médicos e, ao mesmo tempo, passou a acreditar que o saber da medicina trazia respostas eficientes (RABELLO, 2010).

Desta cooperação entre políticos e higienizas culminam normativas que antevêem o que se chama antigamente de proteção social, o Estado de bem-estar social. Até meados do século XX, a seguridade social era instituída em vários países (RABELLO, 2010). O significado de "estar doente" para a proteção social significava "estar sob cuidado" (ADAM; HERZLICH, 2001). Diante disso, a medicina se instituiu como política pública de saúde, sobre uma prática reducionista de saúde centrada na prática clínica. Nesse contexto, a biomedicina se configura no saber médico, desprovida de ações eficientes sobre os determinantes e as condições sociais. Estabelecem-se também as ações e os serviços de saúde de prática curativista-individual em vez de coletivas e preventivas, o lócus de prestação de serviços curativos é inserido nos hospitais; e na Atenção Primeira da Saúde (APS), preconizase a quantidade em detrimento da qualidade das ações e a subjetividade, característica peculiar da relação médico-paciente cede lugar à objetividade racionalista (CAMPOS, 2010; MACIEL-LIMA, 2004; MARTIN et al., 2011; RABELLO, 2010; TADDEO, 2012).

A produção teórica no campo da Saúde Coletiva reconheceu a saúde ao longo do tempo como resultado do enquadramento de elementos sociais, subjetivos e biológicos na experiência coletiva e individual. Essa abordagem possibilita a compreensão de que o tema saúde inclui-se no social, não sendo simplesmente clínico, e está diretamente relacionado com o formato da sociedade e do Estado (RABELLO, 2010).

A saúde, como produção social e histórica, remete-se à produção de políticas de proteção social, as quais resguardariam os cidadãos das adversidades da organização social e das iniquidades sanitárias. A saúde entendida como decorrência deste planejamento, impõe 
aos sanitaristas um "refletir" em saúde, em que, como campo científico e tecnológico, sua ação é sempre aquém do necessário e limitada, porque interfere decisivamente nos fatores sanitaristas, decorrentes do arranjo social e econômico.

Nesta concepção, implica-se uma visão eco-social ao processo saúde-doença, abrindo caminho para uma perspectiva de inter-setorialidade e integralidade das ações coletivas em saúde pública. Reconfigura-se assim, o pensar clínico-epidemiológico da vigilância sanitária, como interesse coletivo da saúde para uma óptica ampliada, contemplando a formulação de políticas públicas saudáveis e de intervenção social nos seus distintos modos de conduzir a vida.

Nesse sentido, incorporam-se novos atores ao envolver a coletividade organizada, extrapolando o conjunto de profissionais e trabalhadores da saúde. Logo, amplia-se o objeto real como intervenção, abarcando determinações que afetam diferentes grupos sociais em detrimento de suas condições de vida e saúde (TEIXEIRA; PAIM; VILASBÕAS, 1998). Destarte, contextualiza-se um processo de integração político social a um modelo de vigilância da saúde.

Figura 2 - Modelo político-sanitário da saúde no contexto do Sistema Único de Saúde

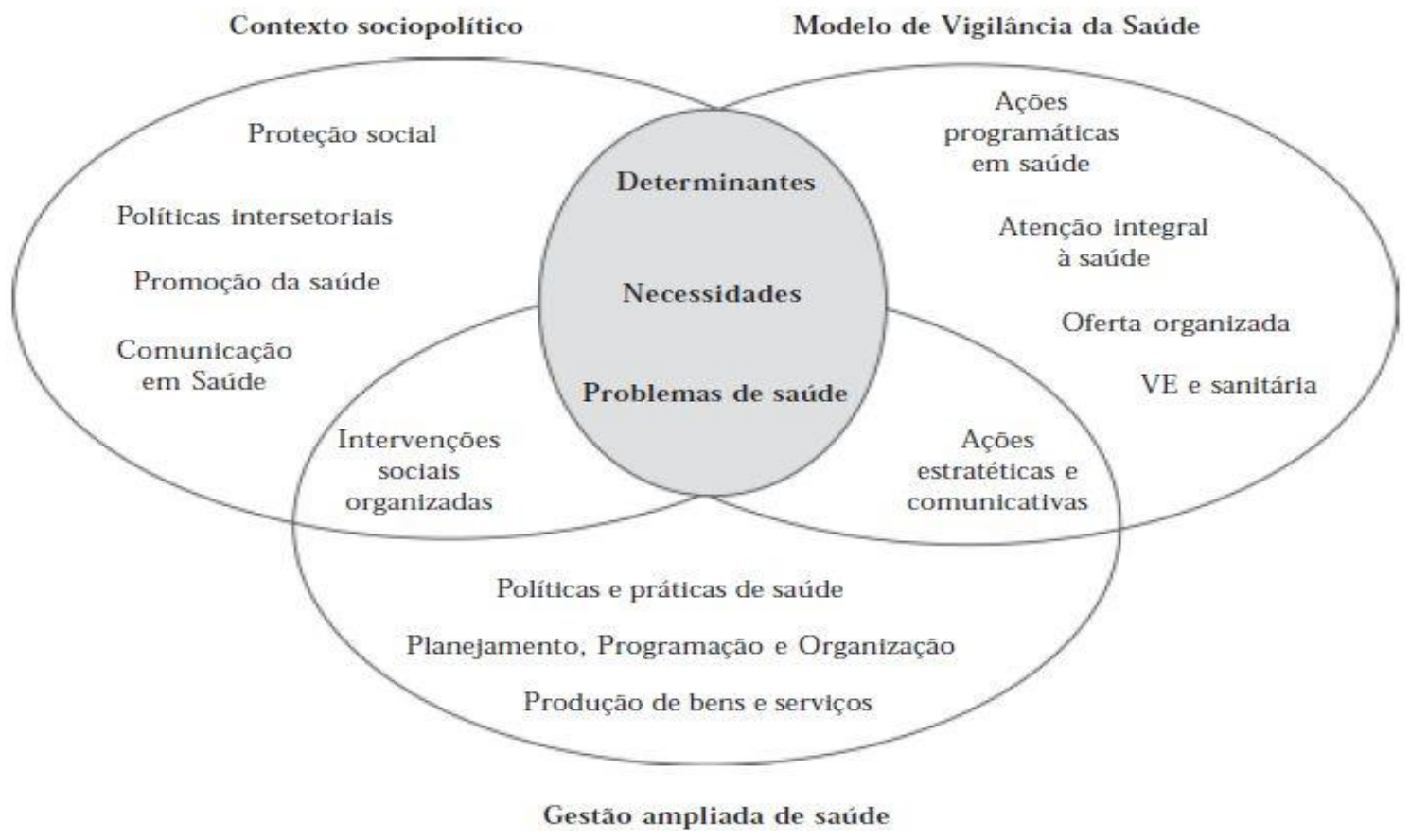

Fonte: Arreaza e Moraes (2010, p. 7) adaptado por TEIXEIRA; PAIM; VILASBÔAS, 1998). 
Assim sendo, extrapola-se o pensar da prática clínica e interliga-se a saúde a um contexto político-sanitário, o qual é caracterizado como sendo de comunicação social, de integração com participação social, de inter-setorialidade, de empoderamento e com uma gestão ampliada em saúde. Desse modo, há uma mobilização de uma ação pública dos distintos grupos de interesse com base na promoção e na defesa dos modos de vida com saúde.

A Promoção da Saúde (PS) organiza-se, transcendendo os espaços institucionais das ações e dos serviços de saúde, se estendendo a outras conjunturas sociopolíticas de ação do Estado e da sociedade civil, envolvendo uma rede complexa de grupos de interesses comprometidos com as políticas e práticas da PS.

Assim sendo, assume-se que a saúde, em um conceito amplo, pauta a discussão sobre a qualidade de vida e pressupõe que a solução dos problemas está no potencial de contar com parceiros, de mobilização social e de gestão organizacional dos sistemas de saúde. Trabalhase com o princípio de autonomia dos indivíduos e das comunidades, reforçando o planejamento e o poder local. Estabelece-se ainda, como pré-requisito essencial de transformação nas condições de vida para a saúde, a necessidade de justiça social, de equidade, de educação, de trabalho, de moradia, de salários adequados e de saneamento, a fim de garantir condições de vida digna e possibilitar que indivíduos e coletividades tenham maior controle sobre os determinantes de saúde (WORLD HEALTH ORGANIZATION, 2005).

Para tanto, diversas são as estratégias priorizadas, como o destaque e a formulação de políticas públicas saudáveis, a reorientação das ações e dos serviços de saúde, a criação de ambientes sustentáveis, o desenvolvimento das capacidades dos sujeitos, o conceito de subjetividade e o fortalecimento de ações comunitárias (CARVALHO; GASTALDO, 2008). Subsidiando essas estratégias faz-se necessário expor a relevância de se atuar nos determinantes e nas causas da saúde, além da participação social e da educação em saúde em um sentido mais amplo, não apenas focando nos hábitos e nos estilos de vida dos indivíduos (CAMPOS; BARROS; CASTRO, 2004). Por fim, a PS configura-se em um processo em construção da saúde pública e na realidade social (RABELLO, 2010).

A Constituição Federal de 1988 determinou ser dever do Estado garantir saúde a toda a população. Para tanto, criou o Sistema Único de Saúde (SUS). Os princípios doutrinários do SUS são: universalidade, integralidade e equidade. A universalidade diz respeito ao atendimento de todo e qualquer cidadão sem distinção. Sendo assim, passa a ser um direito do cidadão e dever do Estado. A Integralidade envolve a forma de gestão e a prestação do serviço ao cidadão. Dessa forma, o Estado deve ter um conjunto de ações envolvendo desde 
atividades simples até as mais complexas. E a equidade, o Estado tem como dever tratar todos de forma igualitária, sem distinção, assim, todos são iguais perante a lei sem distinção de qualquer natureza.

No Brasil, a discussão em torno da Promoção da Saúde (PS), como política pública de saúde, dá-se a partir de 1990, e, como área de conhecimento em análise, após uma fase de ordenamento jurídico-legal dos princípios e das diretrizes do projeto de reforma, institucionalizado no Sistema Único de Saúde (SUS). No entanto, sua configuração prática era um desafio político-gerencial na esfera pública, como conjunto coordenado de ações visando à consecução dos seus objetivos.

Para consolidar uma saúde cidadã e social e operacionalizá-la, em 2006, a Portaria $\mathrm{n}^{\mathrm{o}}$ 687, de 30 de março, aprovou a Política de PS, "considerando a necessidade da implantação e da implementação de diretrizes e de ações para a Promoção da Saúde em consonância com os princípios do SUS" (BRASIL, 2006, p. 5). Em virtude disso, propõe-se que as intervenções sejam ampliadas, tendo por objeto as demandas por saúde, seus determinantes e condicionantes, de modo que as ações e os serviços fossem operacionalizados, no âmbito clínico e para além dos muros das unidades de saúde. Deve-se, portanto, fortalecer o exercício da cidadania, além dos modos institucionalizados de controle social, estabelecendo um olhar critico e criativo para mobilização e participação social na esfera pública, de modo a direcionar o planejamento das ações em saúde a sua realidade circunscrita, percebidas e vivenciadas, bem como o agir sanitário deve envolver a co-responsabilidade em favor da vida e no planejamento de ações e serviços em saúde (BRASIL, 2006).

Nesta conjuntura, variáveis como a inter-setorialidade, a integralidade, a participação social, a gestão e o empoderamento (empowerment) demarcaram uma nova concepção política-sanitária no Brasil, como forma de reestruturar a prática tradicional de saúde. Para isso, renova-se o pensamento sanitário de forma a contribuir na construção de políticas públicas que possibilitem responder as demandas sociais em saúde.

Há ainda desafios a serem consolidados para a formação de uma saúde ampliada, a qual visa à articulação de diferentes atores sociais, com planejamento adequado e criativo, objetivando dar visibilidade aos fatores que colocam a população em risco, como a insuficiência de recursos e a pratica da biomédica, defendendo a equidade e incorporando a participação e o controle social na formulação e na implementação de políticas públicas (CAMPOS; BARROS; CASTRO, 2004; RABELLO, 2010).

Os cidadãos podem participar das Conferências da Saúde que ocorrem a cada 4 anos em todos os níveis federativos, e dos Conselhos de Saúde, que ocorre a chamada paridade: 
enquanto os usuários têm metade das vagas, o governo tem um quarto e os trabalhadores outro quarto. Dessa forma, busca-se estimular a participação popular na discussão das políticas públicas da saúde, conferindo maior legitimidade ao sistema e às ações implantadas (SILVA; ROTTA, 2012).

\section{Metodologia de Pesquisa}

A pesquisa foi exploratória e aplicada, porque busca compreender melhor o papel do legislativo municipal no processo de gestão e planejamento do município. Utilizou-se de dados secundários (sistema de proposições legislativa da câmara municipal de Curitiba) e a análise de dados foi essencialmente quantitativa. A pesquisa consolidou-se em 4 etapas, após a compreensão teórica dos termos para análise do legislativo municipal e o SUS.

A primeira etapa foi selecionar os dados brutos no sistema de proposições legislativas da Câmara Municipal de Curitiba (CMC), disponível em http://www.cmc.pr.gov.br/wspl/system/LogonForm.do. Selecionou-se os dados de projetos lei entre 2008 e 2011, o que constituiu o final do mandato dos vereadores em 2008 e os três primeiros anos do próximo mandato. Verificou-se que os projetos de lei ordinária são os mais representativos em quantidade totalizando 590 projetos. Selecionaram-se os mesmos, para análise mais detalhada. As informações foram coletadas no site da própria Câmara Municipal de Curitiba, durante o período de novembro de 2011 a fevereiro de 2012.

A segunda etapa consistiu em criar uma base de dados com os dados obtidos no sistema, nesta ordem: Iniciativa; Área do Projeto e Ementa. A terceira etapa contabilizou-se a quantidade de vereadores e projetos por área, colocando esses dados em uma tabela dinâmica e criando seus respectivos gráficos. Finalmente, fez-se a análise dos dados sob a forma de tabelas e gráficos, analisando a iniciativa, ementa e área da saúde, bem como se retomou as informações de projetos específicos para compreender melhor alguns detalhes dos números consolidados.

A cidade de Curitiba é a capital do Paraná, foi fundada em 29 de março de 1693, quando foi criada a Câmara. O Município de Curitiba é dividido em oito Administrações Regionais que abrangem 75 bairros (GUIA GEO-PARANÁ, 2015).

No ano de 2008 a Cidade de Curitiba tinha 1.254.776 eleitores aptos e 38 vagas para vereadores, entretanto durante os 4 anos 53 vereadores legislaram na CMC. Quanto aos motivos de saída dos vereadores são diversos, com destaque para alteração de cargo e falecimento, além de outros. 
Figura 3 - Mapa das Regiões Administrativas e Bairros, 2005.

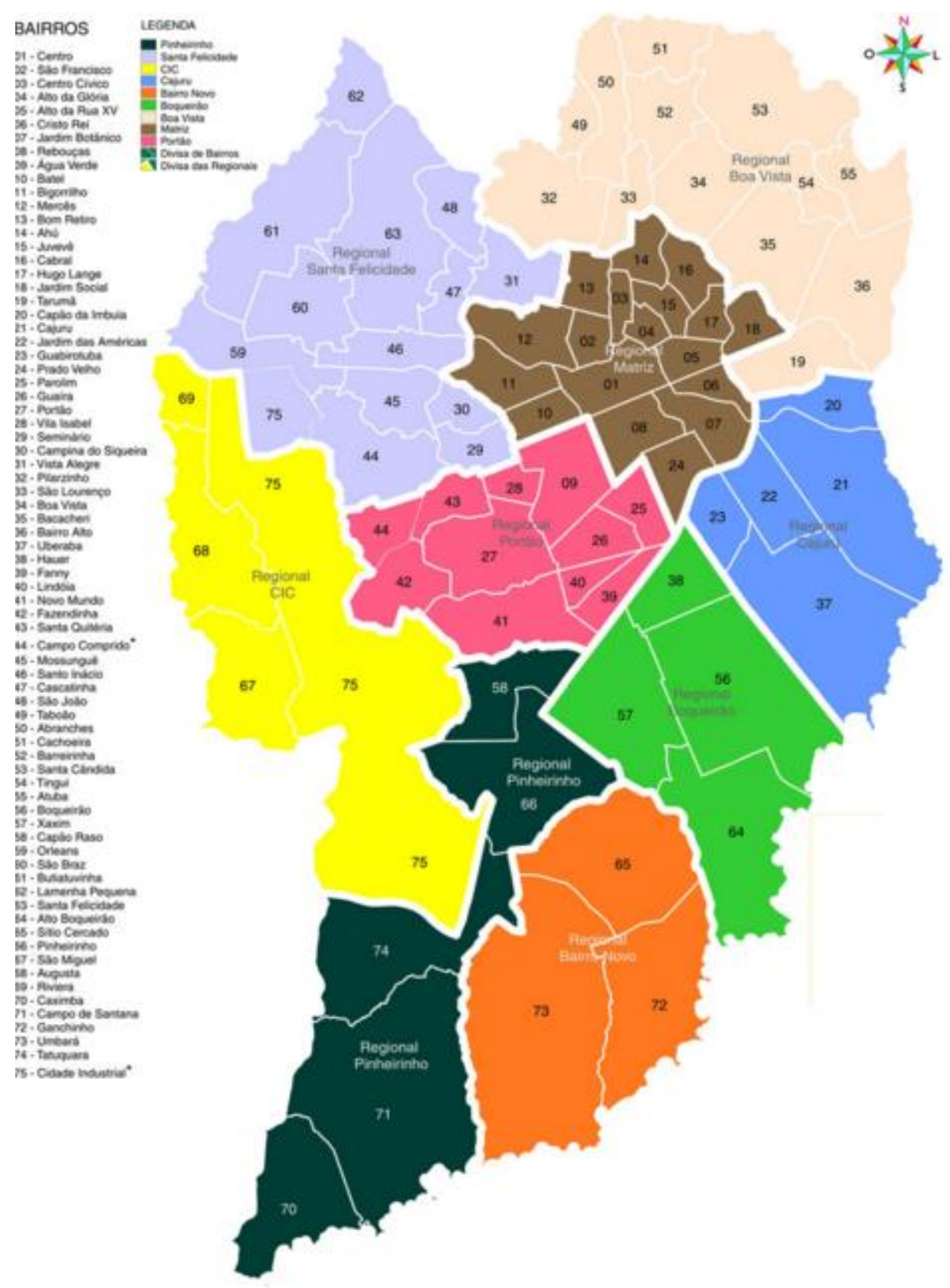

Fonte: IPPUC, 2005.

\section{Análise de Resultados}

O procedimento de elaboração de uma lei ordinária denomina-se processo legislativo ordinário e apresenta as seguintes fases: fase introdutória, fase constitutiva e fase complementar. 
$\mathrm{Na}$ fase introdutória ocorre a iniciativa de lei é a faculdade que se atribui a alguém ou a algum órgão para apresentar projetos de lei ao legislativo, podendo ser parlamentar ou extra parlamentar e concorrentes ou exclusiva. Trata do poder de iniciativa (AGUIAR, 1973).

Fase Constitutiva: nessa fase, uma vez apresentado o projeto de lei ao Congresso Nacional, haverá ampla discussão e votação sobre a matéria nas duas Casas, delimitando-se o objeto a ser aprovado ou mesmo rejeitado pelo Poder Legislativo. Além da atividade Legislativa, na chamada deliberação parlamentar, caso o projeto de lei seja aprovado pelas duas Casas Legislativas, haverá participação do chefe do Poder Executivo, por meio do exercício do veto ou da sanção (deliberação executiva). Tratando-se de lei Ordinária, a aprovação do projeto de lei condiciona-se a maioria simples dos membros da respectiva Casa, ou seja, somente haverá aprovação pela maioria dos votos, presente a maioria absoluta de seus membros, nos termos do art.58, $\S 2^{\circ}$, I, da Constituição Federal. Trata da deliberação parlamentar e da deliberação executiva (AGUIAR, 1973).

$\mathrm{Na}$ fase Complementar compreende a promulgação e a publicação da lei, sendo que a primeira garante a executoriedade à lei, enquanto a segunda lhe dá notoriedade. $\mathrm{O}$ decreto lei é um decreto executivo com força de lei. Através do decreto lei, o chefe do Executivo, exercendo atribuições do Legislativo e do Executivo a um só tempo, dita normas que deveriam ser objeto de lei e, por isso mesmo, haveriam de ser apreciadas e votadas pelo Legislativo. Pelo decreto lei, o Executivo legisla, passando a exercer sozinho, funções de natureza legislativa (AGUIAR, 1973).

Durante os 4 anos em análise foram produzido 590 projetos de lei ordinária, especificamente da área da saúde foram produzidos 16,2\% dos projetos, totalizando 96 projetos. Os projetos referentes à área de segurança correspondem a 10,3\%, totalizando 61 projetos. A área de educação corresponde a $9,49 \%$ dos projetos, totalizando 56 projetos. A área de cidadania corresponde a 51,6\%, totalizando 305 projetos e a área do meio ambiente corresponde a $12,2 \%$, totalizando de 72 projetos (gráfico 1 ). 
Gráfico 1 - Quantidade total de projetos por área - Cidade de Curitiba - 2008 a 2011.

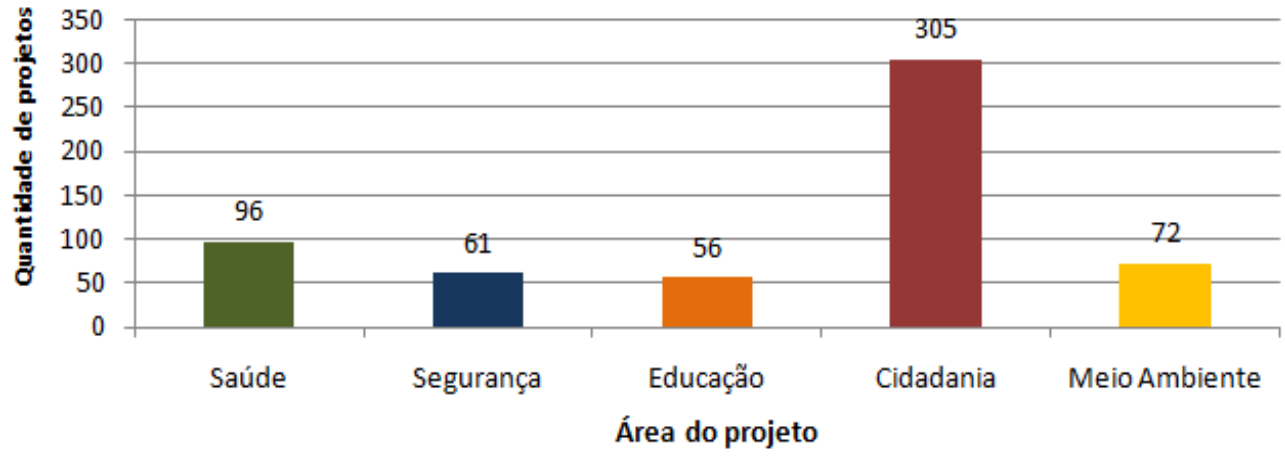

Fonte: Dados brutos, Câmara Municipal de Curitiba, 2011.

Quanto à atuação dos vereadores, pode-se observar a produção média de projetos lei por partido político. Pode-se observar que o PSDB é o partido político com maior número de representantes e produziu a maior quantidade de projetos lei. Entretanto, analisando a média, esse partido produziu menos do que outros partidos com menor número de vereadores (tabela $1)$.

Tabela 1 - Avaliação da produção dos Partidos Políticos Cidade de Curitiba - 2008 a 2011

\begin{tabular}{cccc}
\hline Partido Político & $\begin{array}{c}\text { Percentual de } \\
\text { vereadores por } \\
\text { Partido Político }\end{array}$ & $\begin{array}{c}\text { Percentual de Projetos Lei } \\
\text { por Partido Político na área } \\
\text { da saúde }\end{array}$ & $\begin{array}{c}\text { Média de } \\
\text { Projetos por } \\
\text { Partido Político }\end{array}$ \\
\hline PR & $1,90 \%$ & $0,00 \%$ & 0 \\
PRB & $1,90 \%$ & $0,00 \%$ & 0 \\
PRP & $1,90 \%$ & $0,00 \%$ & 0 \\
PSC & $1,90 \%$ & $1,10 \%$ & 1 \\
PSL & $1,90 \%$ & $7,30 \%$ & 7 \\
PRTB & $1,90 \%$ & $0,00 \%$ & 0 \\
PTB & $1,90 \%$ & $0,00 \%$ & 0 \\
PC do B & $1,90 \%$ & $0,00 \%$ & 0 \\
PPS & $3,80 \%$ & $10,40 \%$ & 5 \\
PSD & $3,80 \%$ & $2,10 \%$ & 1 \\
PMDB & $5,70 \%$ & $5,20 \%$ & 1,7 \\
PDT & $5,70 \%$ & $2,00 \%$ & 0,67
\end{tabular}




\begin{tabular}{cccc} 
DEM & $5,70 \%$ & $4,10 \%$ & 1,3 \\
PP & $5,70 \%$ & $11,50 \%$ & 3,7 \\
PT & $7,50 \%$ & $3,10 \%$ & 0,75 \\
PV & $7,50 \%$ & $4,20 \%$ & 1 \\
PSB & $9,40 \%$ & $7,30 \%$ & 1,4 \\
PSDB & $30,20 \%$ & $41,70 \%$ & 2,5 \\
\hline
\end{tabular}

Fonte: Dados brutos, Câmara Municipal de Curitiba, 2011.

Segundo a tabela 2 , apenas $12 \%$ dos projetos lei ordinária da área da saúde foram aprovados, grande parte $22 \%$ está em análise pelas comissões.

Tabela 2 - Estado dos projetos lei Ordinária da área da saúde - Cidade de Curitiba - 2008 a 2011

\begin{tabular}{|c|c|c|}
\hline Estado do Projeto & $\begin{array}{l}\text { Quantidade de } \\
\text { Projetos }\end{array}$ & $\underset{\text { lei }}{\text { Percentual dos projetos }}$ \\
\hline $1^{\circ}$ turno adiado & 1 & $1 \%$ \\
\hline $2^{\circ}$ turno adiado & 1 & $1 \%$ \\
\hline $\begin{array}{l}\text { Aguardando ação ou manifestação do } \\
\text { Executivo }\end{array}$ & 3 & $3 \%$ \\
\hline Aguardando análise da redação final & 0 & $0 \%$ \\
\hline Aguardando análise em $1^{\circ}$ turno & 15 & $16 \%$ \\
\hline Aguardando sanção ou veto & 0 & $0 \%$ \\
\hline Anexada por semelhança & 8 & $9 \%$ \\
\hline Arquivada pelas Comissões & 13 & $14 \%$ \\
\hline Arquivada por final de legislatura & 3 & $3 \%$ \\
\hline Em análise pelas Comissões & 20 & $22 \%$ \\
\hline Em tramitação & 0 & $0 \%$ \\
\hline Prazo recursal / Arquivamento & 1 & $1 \%$ \\
\hline Prejudicada & 0 & $0 \%$ \\
\hline Promulgada com veto parcial mantido & 1 & $1 \%$ \\
\hline Promulgada/sancionada & 10 & $11 \%$ \\
\hline Rejeitada em Plenário & 1 & $1 \%$ \\
\hline Retirada pelo autor & 17 & $19 \%$ \\
\hline Veto total mantido & 2 & $2 \%$ \\
\hline
\end{tabular}

Fonte: Dados brutos, Câmara Municipal de Curitiba, 2011. 
Nota: Quanto as situações dos projetos lei, essas têm significados diferentes: $1^{\circ}$ turno adiado o projeto lei é adiado a sua discussão para uma oportunidade posterior devido algum motivo. Projetos em $2^{\circ}$ turno adiado refere-se ao projeto lei que já passou por algumas fases, mas é adiada a sua discussão para uma oportunidade posterior devido algum motivo. Aguardando ação ou manifestação do Executivo os projetos esperam alguma decisão do Executivo. Aguardando análise em $1^{\circ}$ turno o projeto lei está aguardando ser analisado em uma de suas primeiras fases. Aguardando análise da redação final o projeto lei já passou por várias etapas e está sendo examinada a redação final. Aguardando sanção ou veto o projeto está em fase final para se tornar lei, e poderá ser vetado ou sancionado. Anexada por semelhança o projeto é anexado, pois já existe um projeto lei semelhante, o qual é julgado ser mais adequado. Arquivada pelas Comissões o projeto lei foi arquivado, guardado pelas Comissões por algum motivo. Arquivada por final de legislatura: o projeto lei é arquivado quando o governante chegou ao final do seu mandato. Em análise pelas Comissões: o projeto lei está sendo estudando em todas as suas partes pelas Comissões. Em tramitação o projeto lei está passando por todas as etapas antes da conclusão final. Prejudicada o projeto lei sofreu algum prejuízo. Prazo recursal /Arquivamento o projeto lei pode ser reconsiderado ou arquivado. Prejudicada o projeto lei sofreu algum prejuízo, foi anulado. Promulgada com veto parcial mantido é promulgada, mas se veta apenas alguns artigos do projeto de lei. Promulgada/sancionada é declarar que uma nova lei passa a existir e que, consequentemente, deve ser cumprida. Assim, é a promulgação que garante executoriedade à lei. Rejeitada em Plenário o projeto lei passou por várias fases, mas foi rejeitado no Plenário. Retirada pelo autor o governante decide retirar o seu projeto lei, pois julga ser a melhor decisão, podendo ser por vários motivos, um deles seria proposições com objetivos semelhantes. Veto total mantido o projeto de lei é arquivado definitivamente, pois esse já foi julgado e vetado.

Os projetos lei ordinária da área da saúde, foram analisados de forma detalhada, observou-se que referem-se a questões que envolvem toda a sociedade, desde atendimento preferencial em hospital para idosos, pistas exclusivas para ambulâncias até datas comemorativas.

Para melhor detalhamento, os projetos de lei ordinária referente à área da saúde foram divididos nas seguintes categorias: datas comemorativas referente à área da saúde, proibições, preferências para grupos específicos, obrigatoriedade, impacto para o serviço público e uma categoria denominada "outros".

Os projetos de lei ordinária que se enquadraram na categoria "datas comemorativas referente à área da saúde" são:

1. Semana de prevenção do diabetes e a hipertensão arterial.

2. Dia municipal da conscientização da cardiopatia congênita.

3. Semana municipal da saúde do homem.

4. Municipal do terapeuta holístico.

5. Semana da mulher grávida, e outras datas comemorativas.

Esses projetos de lei representam $11,46 \%$ dos projetos de lei ordinária da área da saúde.

Quanto à categoria "proibições", alguns dos projetos de lei ordinária são:

6. Proibição do uso de materiais ou artefatos que contenham quaisquer tipos de amianto ou asbesto, ou mesmo outros minerais que, acidentalmente, tenham fibras de amianto na sua composição. 
7. Proibição da cobrança de taxas ou valores por maternidades particulares para que acompanhante assista ao parto dentro do centro obstétrico.

8. Proibição da cobrança de valores para utilização de estacionamento de veículos nos hospitais, clínicas, prontos-socorros e estabelecimentos congêneres.

9. Proibição em todo território do Município o uso dos equipamentos para bronzeamento artificial por meio da emissão de radiação ultravioleta (UV) com finalidade estética.

Os projetos referentes à categoria "proibições" representam $8,3 \%$ do total de projetos de lei ordinária referente à área da saúde.

Analisando a categoria denominada "preferências para grupos específicos", alguns dos projetos são:

10. Atendimento prioritário para idosos em unidades vinculadas ao Sistema Único de Saúde, em consultas com especialistas e exames em geral.

11. Favorecimento aos doadores de sangue, quanto ao atendimento nas unidades de saúde municipais.

12. Cobrança de meia-entrada em eventos culturais para doadores de sangue como também de medula óssea.

13. Agendamento telefônico de consultas médicas para pacientes idosos e/ou portadores de deficiência, previamente cadastrados nas unidades de saúde municipais.

14. Favorecimento aos doadores de sangue, quanto ao atendimento nas unidades de saúde municipais.

Os projetos referentes à categoria "preferências para grupos específicos", representam $13,54 \%$ do total de projetos de lei ordinária referente à área da saúde.

Alguns dos projetos de lei ordinária que se enquadraram na categoria "obrigatoriedade" são:

15. Torna-se obrigatório a utilização pulseira com sensor eletrônico sonoro, para identificação e segurança de recém-nascido, nos hospitais e nas maternidades públicas e privadas na cidade de Curitiba.

16. Torna-se obrigatório a fixação de quadro informativo nos hospitais, prontossocorros e Unidades de Saúde.

17. Torna-se obrigatório a fixação de preços, esterilização e informações sobre produtos utilizados pelos estabelecimentos de tratamento de beleza, estética e congênere. 
18. Torna-se obrigatório o fornecimento e uso de protetor solar para empregados de todas as empresas, públicas ou privadas, que no exercício de suas atividades, estejam expostos à radiação solar.

19. Torna-se obrigatório a realização de exame diagnóstico para detecção de catarata congênita em crianças recém-nascidas nos estabelecimentos hospitalares na Cidade de Curitiba.

Além desses projetos há outros referentes a essa categoria. Esses projetos de lei representam 19,8\% dos projetos de lei ordinária da área da saúde.

Quanto à categoria "impactos para o serviço público", são projetos que terão impactos na administração pública e na oferta do serviço público, alguns dos projetos de lei ordinária são:

20. Autorização do Executivo Municipal de Curitiba a realizar convênio com o Governo Estadual, através da Secretaria Estadual de Saúde; Governo Federal, através do Ministério da Saúde; outros órgãos federais afins, e Prefeituras da Região Metropolitana de Curitiba, para construção e/ou instalação do Hospital Regional Metropolitano em um dos bairros do Grande Boqueirão.

21. Fornecimento pela internet de resultados de exames pelo laboratório municipal de Curitiba.

22. Comunicação via mensagem de celular e mensagem de email, informações aos pacientes referente a consultas médicas e exames médicos previamente agendados na rede municipal de saúde.

23. Autorização ao Poder Executivo a implantar a realização de exame preventivo anual, de saúde nos servidores públicos municipal.

24. Autorização ao Poder Executivo a implantar rede de serviços de atendimento e suporte familiar para portadores de Alzheimer.

Os projetos referentes à categoria "impactos para o serviço público" representam $34,4 \%$ do total de projetos de lei ordinária referente à área da saúde.

Analisando a categoria denominada "outros", são projetos de lei ordinária referente à área da saúde que não foram enquadrados nas categorias anteriores. Alguns desses projetos são:

25. Criação de pista exclusiva para a utilização de veículos automotores que contenham mais de uma pessoa em seu interior, ônibus e veículos em atendimento de Emergência, no sistema viário de Curitiba. 
26. Higienização das cadeirinhas de bebê fixadas em carrinhos de supermercado, hipermercado e congêneres.

27. Dispõe sobre o tempo máximo de espera para o atendimento dos usuários de planos particulares de saúde junto aos serviços em que se encontrem conveniados.

Os projetos referentes à categoria "impactos outros" representam 12,5\% do total de projetos de lei ordinária referente à área da saúde.

Pode-se observar que os projetos de lei ordinária referente à área da saúde estão relacionados a toda população. A maioria dos projetos está relacionada ao impacto no serviço público e a minoria a datas comemorativas relacionadas à área da saúde.

Portanto, pode-se observar que durante os 4 anos em análise foram produzidos 96 projetos lei ordinária na área da saúde, e apenas 11 projetos lei foram promulgados/sancionados. Esses são:

28. Obrigatoriedade de todos os estabelecimentos comercias e similares que realizem venda/manipulação de alimentos e também em todas as Unidades de Atendimentos da Prefeitura Municipal de Curitiba, a instalar em local visível e de fácil acesso aos usuários, saboneteira líquida de parede contendo solução álcool gel anti-séptico, bem como, junto a ela, placas/cartazes orientadores que informem a importância da higienização das mãos como ato preventivo a diversos tipos de doenças.

29. Obrigatoriedade dos supermercados e estabelecimentos comerciais que vendam produtos alimentícios, em afixarem cartazes informativos sobre os produtos com data próxima de vencimento.

30. Fixação nas academias de ginástica, nos centros esportivos e estabelecimentos comerciais de nutrição esportiva e produtos correlatos à atividade física, de carta com advertência sobre as consequências do uso de anabolizantes.

31. Fixação obrigatória de placa informativa em farmácias e drogarias no âmbito do Município de Curitiba, contendo advertência quanto aos riscos da automedicação em geral.

32. Restrições ao uso de produtos fumígenos no Município de Curitiba.

33. O atendimento emergencial em eventos de grande porte na Cidade de Curitiba.

34. Criação do programa de esclarecimento e conscientização sobre a Esclerose Múltipla.

35. Criação do Dia Municipal de Conscientização da Cardiopatia Congenita, a ser comemorado anualmente, no dia 12 de junho.

36. Criação do Dia da Alimentação Saudável.

37. Criação da "Semana da mulher grávida", no âmbito do Município de Curitiba. 
38. Criação do Dia municipal da comunidade terapêutica.

Pode-se observar que grande parte dos projetos sancionados estão relacionados com datas comemorativas. O objetivo é chamar a atenção da sociedade para determinado tema, sendo assim, são escolhidas algumas datas para prestigiar tal tema. $\mathrm{O}$ município se preocupa mais com a conscientização e com a informação da comunidade do que com a ação em si. Pois poucos projetos, que consistem em ações que causam impactos significativos na sociedade foram aprovados.

Tendo em vista tal fato, pode-se observar a importância do ciclo de políticas públicas para que sejam identificados problemas reais na sociedade, e sejam discutidos com toda a população por meio de audiências públicas, congressos, reuniões, encontros e outros meios. E assim, elaborar programas, projetos e ações que sejam implementadas e tenham efeito positivo para solução do problema. Os governantes devem avaliar e monitorar as ações para verificar estão sendo correspondidas conforme o planejado.

\section{Considerações Finais}

Nesta pesquisa foram analisados os projetos de lei ordinária especificamente na área a saúde e os que se tornaram leis na Cidade de Curitiba durante o período de 2008 a 2011 . Em um processo de desenvolvimento e amadurecimento da democracia brasileira os projetos leis e o acompanhamento das mesmas representam uma importante contribuição à transparência das ações do legislativo.

Pode-se observar, que há vereadores que não propuseram projetos lei na área da saúde. Há partidos políticos com grande número de representantes e em média produziram menos projetos leis do que partidos políticos com menor número de representantes políticos. Outro ponto é a permanência de um significativo número de proposições em tramitação, grande parte dos projetos lei estão na fase de análise pelas comissões $22 \%$ e outros $16 \%$ estão aguardando análise em $1^{\circ}$ turno.

Observou-se que dos 96 projetos lei apenas 11 projetos foram promulgados/sancionados. Esses projetos são importantes para toda a sociedade, alguns tem impacto direto na população, tais como, atendimento emergencial em eventos de grande porte e a disposição de saboneteiras líquida de parede contendo solução álcool gel anti-séptico. Quanto às datas comemorativas, impactam indiretamente a população, mas também são importantes, pois fortalecem certos eventos, mobilizando grande parte da população. Uma parte significativa dos projetos lei está em análise, além de muitos deles serem projetos que causem impactos indiretos na população. 
Por fim, cabe destacar que o processo de governança pública se instaura e inicia no Brasil após a constituição de 1988 por um aumento da transparência e maior demanda por ética pública dos representantes do legislativo e executivo nas três esferas de poder. $\mathrm{O}$ Sistema Único de Saúde foi criado em 1990, resultado de um processo de lutas, mobilização, participação e esforços desenvolvidos por um grande número de pessoas. Os cidadãos podem participar das Conferências da Saúde que ocorrem a cada 4 anos em todos os níveis federativos, e dos Conselhos de Saúde. Portanto, a população deve participar de audiências públicas e seminário para exporem suas opiniões para melhor gestão e planejamento do município.

A necessidade de uma maior participação popular não depende somente do incremento desta transparência de dados e informações, mas da compreensão que isso é relevante para o desenvolvimento do planejamento e gestão dos municípios. $\mathrm{O}$ acompanhamento do que é proposto e o que vira lei é um elemento crucial, como se pode indicar, para fortalecimento desta governança pública. Sabe-se que a saúde pública é uma das áreas mais críticas, sendo uma das mais utilizadas pela população. É necessário ter maior interação entre os governantes e a sociedade, de forma a criar proposições que sejam efetivamente válidas para todos. Os resultados demonstram a necessidade de maior integração e participação da sociedade no Conselho Municipal de Saúde e no debate das proposições do Poder Legislativo municipal para fortalecer o papel local no desenvolvimento e aprimoramento da política pública em saúde.

Assim, deve-se fortalecer o exercício da cidadania, estabelecendo um olhar critico e criativo para mobilização e participação social na esfera pública, de modo a direcionar o planejamento das ações em saúde a sua realidade circunscrita, percebidas e vivenciadas, bem como o agir sanitário deve envolver a co-responsabilidade em favor da vida e no planejamento de ações e serviços em saúde. Portanto, é necessário compreender como o legislativo é importante no processo de amadurecimento da democracia em todos os níveis de governo.

Agradecimentos: A Universidade Tecnológica Federal do Paraná e a Fundação Araucária proporcionarem o financiamento, condições e oportunidades de aprendizado e pesquisa sobre a Administração Pública Brasileira em seus aspectos relacionados à Governança Pública e ao Planejamento e Desenvolvimento do Estado. 


\section{REFERÊNCIAS}

ADAM, P; HERZLICH, C. Sociologia da Doença e da Medicina. São Paulo: Edusc, 2001.

AGUIAR, J. C. Processo Legislativo Municipal. Rio de Janeiro, RJ: Forense, 1973.

ARREAZA, A. L. V; MORAES, J. C. Vigilância da saúde: fundamentos, interfaces e tendências. Ciência \& Saúde Coletiva., Rio de Janeiro. v. 15, n. 4, p. 2215-2228, jul. 2010. Disponível em: <http://www.scielo.br/pdf/csc/v15n4/a36v15n4.pdf>. Acesso em: 28 out. 2012.

BRASIL. Ministério da Saúde. Política Nacional de Atenção Básica, Brasília, 2006. v. 2006. Disponível em: $<$ http://portal.saude.gov.br/portal/arquivos/pdf/pactovolume7.

pdf $>$. Acesso em: 12 nov. 2012

CÂMARA MUNICIPAL DE CURITIBA (2012). Vereadores dados e contato. Disponível em: http://www.cmc.pr.gov.br/ver.php. Acesso em: 20 março 2012.

BIRKLAND, T.A. An introduction to the policy process: theories, concepts, and models of public policy making. 2.ed. Armonk, Nova York: M.E. Sharpe, 2005.

CAMPOS, G. W; BARROS, R. B; CASTRO, A. M. Avaliação de política nacional de promoção da saúde. Ciência \& Saúde Coletiva. Rio de Janeiro, v. 9, n. 3, p. 745-749, jul./set. 2004. Disponível em: <http://www.scielo.br/pdf/csc/v9n3/a20v09n3.pdf>. Acesso em 9 dez. 2012.

CARVALHO, S. R; GASTALDO, D. Promoção á saúde e empoderamento: uma reflexão a partir das perspectivas crítico-social pós-estruturalista. Cienc. e Saúde Coletiva., Rio de janeiro, 13(Sup 2), p. 2029 - 2040, jun. 2008. Disponível em: $<$ http://www.scielo.br/pdf/csc/v13s2/v13s2a07.pdf >. Acesso em: 30 out. 2012.

DYE, T. R. Understanding public policy. 13 ed. United States: Pearson Education/ Longman, 2011.

GUIA GEO-PARANÁ. Bairros de Curitiba. Disponível em: <http://www.curitibaparana.net/bairros.htm>. Acesso em: 14 de outubro de 2015.

INSTITUTO DE PESQUISA E PLANEJAMENTO URBANO DE CURITIBA. Mapa e Bairros. Disponível em: $<$ http://www.ippuc.org.br/default.php>. Acesso em: 22 de outubro de 2015.

LIMA. S. M. L et al., Utilização de diretrizes clínicas e resultados na atenção básica á hipertensão arterial. Cad. Saúde Pública. Rio de Janeiro, v. 25, n. 9, p. 2001-2011, set. 2009. Disponível em: <http://www.scielo.br/pdf/csp/v25n9/14.pdf>. Acesso em: $17 \mathrm{dez}$. 2012 .

MACIEL-LIMA, S. M. Acolhimento solidário ou atropelamento? A qualidade na relação profissional de saúde e paciente face á tecnologia informacional. Cad. Saúde Pública. Rio de Janeiro, v. 20, n. 2, p. 502-511, mar./abr. 2004. Disponível em: $<$ http://www.scielosp.org/pdf/csp/v20n2/18.pdf $>$. Acesso em: 02 nov. 2012. 
MORAES, A. D. Direito Constitucional. 25. Ed. São Paulo: Atlas, 2010.

PAIM, S. J; TEIXEIRA, C. F. Política, planejamento e gestão em saúde: balanço do estado da arte. Rev. Saúde Pública., São Paulo, 40 (N esp), p. 73 - 78, ago. 2006. Disponível em: $<$ http://www.scielo.br/pdf/rsp/v40nspe/30625.pdf > . Acesso em: 28 out. 2012.

PETERS, B. G. Review: Understanding Governance: Policy Networks, Governance, Reflexivity and Accountability by R. W. Rhodes. Public Administration 76: 408-509. 1998.

RABELLO, L. S. Promoção da Saúde: a construção social de um conceito em perspectiva comparada. Rio de janeiro: Fiocruz, 2010.

SILVA C. L; ROTTA C. V. O dilema da universalidade e financiamento público do Sistema Único de Saúde do Brasil. Textos e Contextos. Porto Alegre, v. 11, n. 2, p. 333-345 ago./dez. 2013.

SILVA, C.L (org). Políticas Públicas e desenvolvimento local: instrumentos e proposições de análise para o Brasil. Petrópolis, RJ: Vozes, 2012.

SOUZA, C. Políticas Públicas: uma revisão da literatura. Sociologias, 16, jun-dez, p. 20-45, 2006.

TADDEO, P. S. et al. Acesso, prática educativa e empoderamento de pacientes com doenças crônicas. Cienc. e Saúde Coletiva., Rio de Janeiro, v. 17, n. 11, p. 2923-2930, jul. 2012. Disponível em: <http://www.scielo.br/pdf/csc/v17n11/v17n11a08.pdf>. Acesso em: 18 dez. 2012.

Recebimento dos originais: 09/09/2015

Aceitação para publicação: 26/11/2015 